\title{
Energy Efficiency in Architecture - a Technical Obstacle or a Chance to Find new Forms?
}

\author{
Nikolai Shchepetkov ${ }^{1, *}$ \\ ${ }^{1}$ Moscow Architectural Institute (State Academy), 107031 Rozhdestvenka st, 11, Moscow, Russian \\ Federation
}

\begin{abstract}
The article exposes innovative materials and structures for improving the energy efficiency of lightning in architecture. The problem of architectural energy efficiency and its part - energy saving illumination of rooms and urban environment is very actual in developing countries. This problem can be successfully solved only by a complex of architectural, constructional, electrical and technological measures which will lead to new forms in architecture and lightning design. This article briefly reviews the benefits of light pipes technologies to enhance natural illumination of deep plan buildings.
\end{abstract}

\section{Introduction}

The point of architecture as a "foremother" of all kinds of art is to create an art image environment, if its objects could be ranked as expressive artworks, not only as a result of construction. In this case we are talking about architectural forms which are created by our visual impressions (there are also other art forms: music, literature, painting, scenic).

And the vision is impossible without light. Any light, natural or artificial, has its absolute autonomy, because it is the existence form of matter which consists of electromagnetic waves. Light is primary in the environment and is necessary for human to visually perceive objects and spaces, including architecture, which becomes the secondary source of light in this process, reflecting the light from optic primary sources like sun, sky, fire, electric lights.

We can state that exactly the light turns architecture into a figurative art if the dimensional form itself meets the requirements of harmony with that particularly light.

This objective fact is almost lost in the theory of architecture, architectural forms are usually analyzed without considering the lightning conditions, which could illusory change them beyond recognition compared with a certain archetype ("genetically" - with an average daylight).

Its obviousness is exposed in the rapid development of artificial lighting and light created by the expanding kaleidoscope of light forms in the exterior and interior (when the physical parameters of the architectural form are constant), which differ from the traditional day images in its novelty and emotion enhanced by the principles of visual perception in conditions of adaptation to dark $[1,2]$.

*Corresponding author : $\underline{n} \_$shchepetkov@inbox.ru 


\section{The interconnection between the energy-saving architectural form and the light}

Created by the light of primary sources, visual images of architecture during the day are free, because global and inexhaustible natural light in the first half of day was given to us by nature. A man-made artificial light, consuming amount of which is increasing through time and space, costs money. And we often start to calculate those money without considering, for example, the connection between natural and electric light and possibilities for its joint use during the day in an increasing amount of windowless, underground and dimly lit rooms in modern architecture. This is a fundamental problem of methodology of architecture design, the interconnection between the architectural form and the light, hard perceptible formative (literally, not in a figurative sense) impact of the light, primarily natural, to the architecture. To this we must add the cost of not less important and closely related issue of heat-resistance of buildings, the wider the building, the more it is resistant to climate impact, but indoor space requires artificial lighting during the day, which is not rational; the more glass area in the enclosing surfaces of the room to ensure daylight, the more troubles and costs for heating and air conditioning ("glass mania" is still in fashion [3, 4]), etc.

Modern technologies of a "smart house" architecture are oriented mainly on expensive technical "stuffing" with guided engineering systems and effective heat and noise protective materials of walls, and also autonomous systems of alternative, environmental-friendly energy supply. Often the problem of choosing energy efficient architectural form is neglected, with the required minimum of façade and roof glazing, also considering its orientation to cardinals and the wind rose, with a minimum number of façade surface angles, with an efficient ratio of external walling area to the heated volume enclosed in it, etc.

This is the essence of a profession. Historical experience of our ancestors is forgotten, they used to build compact and beautiful buildings in hard climate conditions and they were not really involved into searching for a fashionable, extravagant form. These peculiarities are most obviously seen in the student projects and then they stick in the minds and practical work. Composite searching of expressive forms in studying is certainly priority, but in the case of their analytical support on the above issues, for example, in the essays and the explanatory notes, which is clearly not enough.

\section{Natural, artificial and mixed lighting in the building}

Thus, energy efficiency in architecture is a reasonable, calculated synthesis of architectural form, building materials, engineering and engineering systems. This triad is also related to the lighting of buildings - natural, artificial and mixed.

It is unreasonable to consider them separately. For example, today in the information field and in practice there is a forcing idea of indispensability of LED lighting as an energysaving panacea. In fact it is only a part, promising though, of the general energy-saving strategy for artificial lighting, which shouldn't be dwelled on so much. The problem is much more complex, multifaceted, and, in the case of complex solutions of certain actions, promises great economic benefits.

Where and how can we save energy on lighting without breaking the requirements? According to data published at the beginning of the 21 st century, developed countries spent $35 \%$ of consumed electricity for artificial interior lighting, and only about $1.5 \%$ for outdoor lightning. Perhaps, this ratio is different today due to the rapid development of architectural lighting in the cities, but it is unlikely to have changed fundamentally. 
Thus, lightning design of interior in the first place allows us to save money, and the work in this direction is in progress, the release of new and various LED lamps and luminaires is growing rapidly, and the most common and widely produced devices with fluorescent last generation lamps ( $\mathrm{T}$ 5) for industrial and public buildings have sufficiently high performance.

Only the integration of modern lighting control systems significantly falls behind, which are also an important tool for energy savings. For example, hundreds of thousands of fluorescent lamps illuminate staircases of multi-family housing around the clock, when there is no one there and no light required, and only a small automatic motion sensor is needed. Commercial developers in 2015 launched a fairly simple and affordable lighting control device of the new generation - Celian Smart Switch with traditional switch functions and IR motion sensor. Built-in sensor automatically switches the light off 10 minutes after people leave the room. Widespread replacement of old switches with new ones in all the buildings at once would give a tangible effect.

\section{Light pipes}

One of the most promising ways of energy saving in the daytime, especially in regions with a predominance of sunny weather, is the use of tubular hollow light pipes in the big wide rooms, in the underground and other areas with a lack or absence of natural light (parking lots, warehouses, transport platforms, underpasses etc.). Light pipes are physical structures used for transporting or distributing natural light for the purpose of illumination.

Current light transport technologies include the following (Figure 1) [5]:

1. Lenses,

2. Hollow prismatic pipes,

3. Light rods,

4. Mirrored light pipes

5. Fibre optics

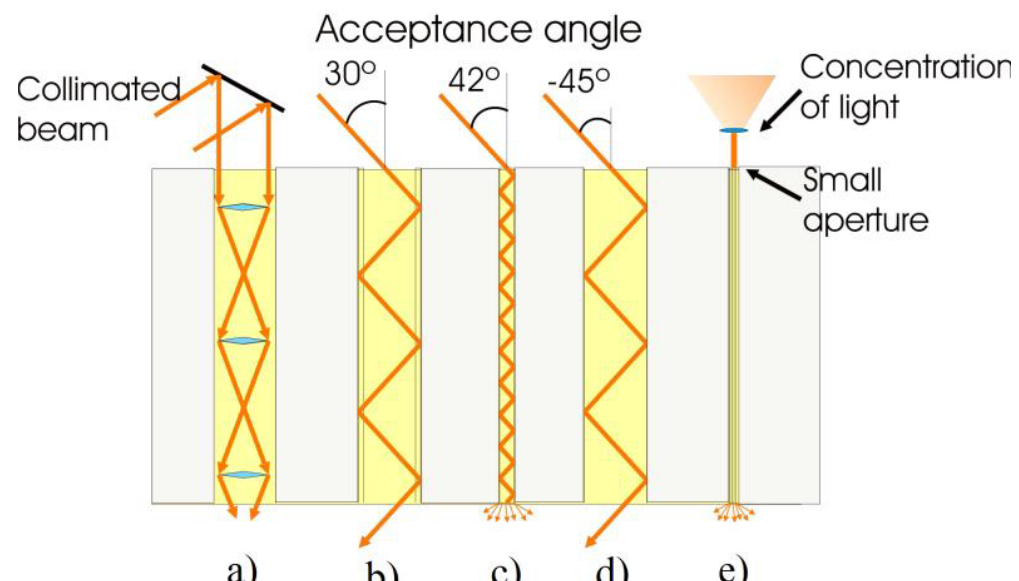
a)
b)
c)
d)
e)

Fig. 1. Different light pipe technologies. a) Lenses; b) Hollow prismatic pipes; c) light rods; d) Mirrored light pipes and e) Fibre optics.

These pipes (Figure 2), widely spread in Italy, England, USA, Canada, Germany, Austria and other developed countries, have a number of light-, sound- and heat engineering and operational advantages over traditional systems of natural illumination of buildings [6] . 


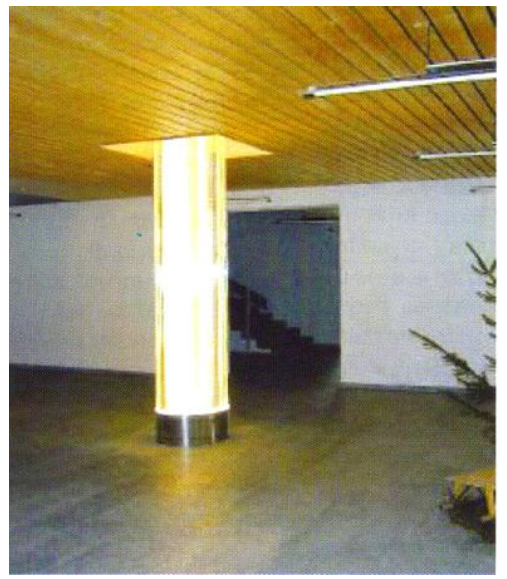

Fig.2. Integrated light pipe «Heliobus» in the school hall in the town of Schiers (Switzerland).

Captured by the receiving optical device outside the building (on the roof, the facade), natural light is transferred by means of mirrored inside pipes to different dark rooms almost lossless for tens of meters vertically and horizontally. Along the way, light can be separated if necessary, concentrated, dissipated, it can change direction and spectrum due to various technical devices. This light in the room is natural, it shows all the changes taking place with an open-air light, which is especially interesting for the light atmosphere in the interior in a cloudy-bright day. The design of the hollow light pipe can contain the installation of artificial light, which eliminates the lack of natural light on a cloudy winter's day or any day at dusk and provide lighting at night (so-called integrated system). If the crowning part of such pipe rises, for example, above the ground in the exterior pedestrian area, in the evening it looks like a light sculpture, locally illuminating the adjacent land area (the area of Potsdamer Platz in Berlin). Figure 3.
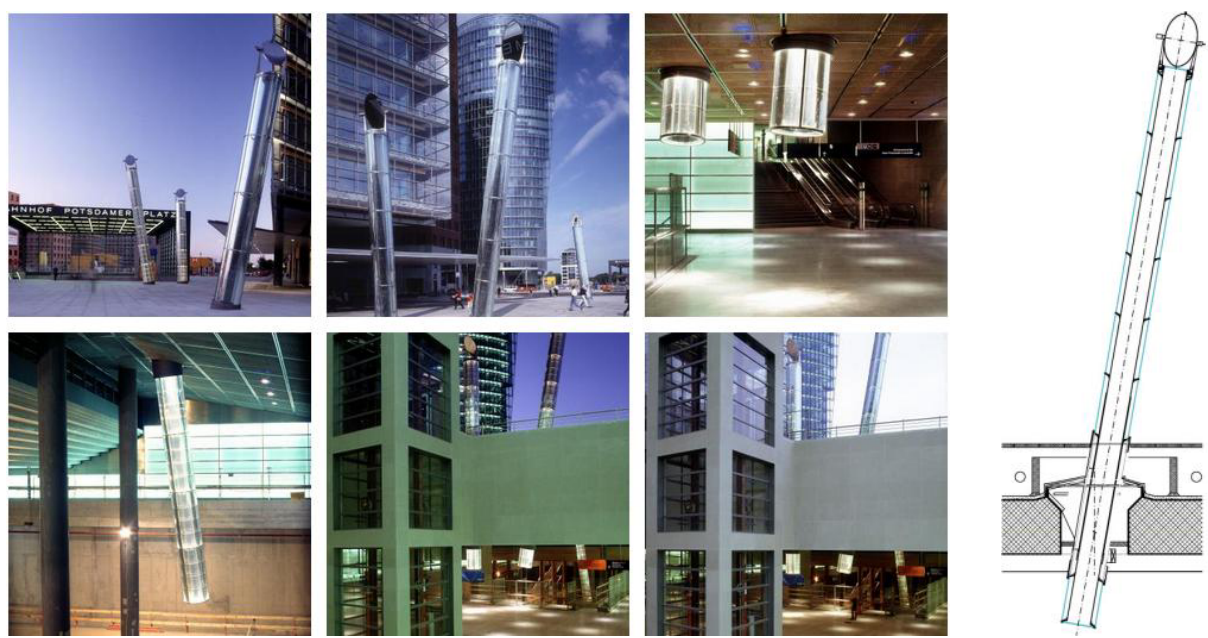

Fig.3. Light pipes located in Potsdam Platz Square in Berlin [8].

Light pipes located in Potsdamer Platz Square in Berlin, which are partly illuminating the platform of underground hall in the afternoon, and used as light sculptures in the evening. 
In Russian projects this ecologically perfect system, unfortunately, almost does not occur, because everybody relies on solar panels which convert the energy of daytime radiation into electricity, and then in the light, for example. The efficiency of such doubleconversion systems is low. It is better to sacrifice a minimum of internal volume for the light pipes, as we do it for ventilation systems, in order to deliver free natural light to the room in the original. Of course, the integration of this method will have some influence on the space-planning design of buildings.

\section{Energy efficient light design}

In some cases with a large built-up area with one-, two- and three-storey buildings, properly designed light well can be energy efficient as a medium element of space-planning design between traditional courtyards and atriums.

In any case, the main purpose of these designs is energy savings on lighting of rooms in the daytime, provided by architectural form. These designs can be original in forms too.

For illumination of underground spaces, method of translucent exploited coatings in the ground level is also effective. Sidewalk, crossing the square in front of the railway station in the city of Tours in France, at night lights with "free" light: it is made of glass bricks for daylight of underground parking and parking artificial lighting at night creates a spectacular light alley on the station area for free (Figure 4).

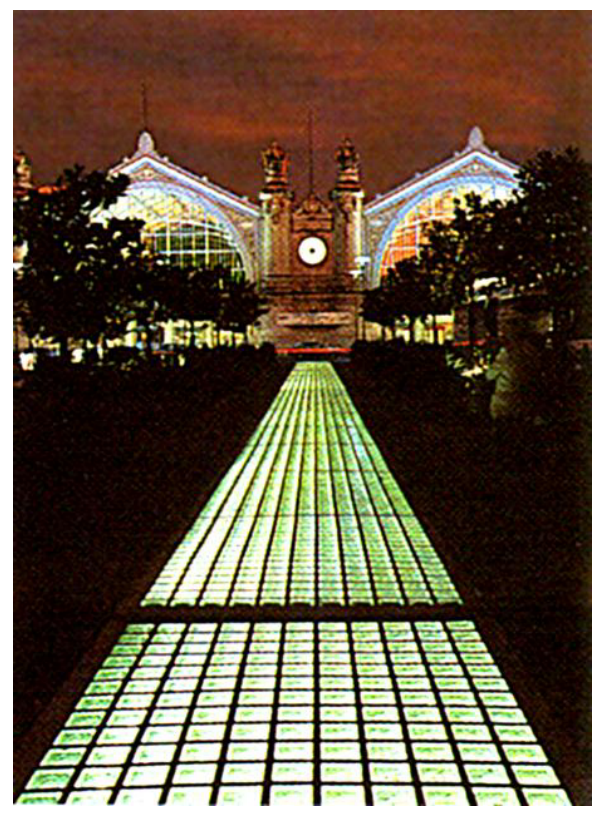

Fig. 4. Glowing at night pavement of glass blocks located above the underground parking at the railway station square in Tours, France.

An urban environment has its reserves and energy saving methods. The main trick is to "address" the electric lighting, which creates in the surrounding darkness optically finite light environment of the city as a system of discrete heterogeneous lightened spaces (within luminaire photometric bodies), which is fundamentally different from the homogeneous global day lightened space (from horizon to horizon through the zenith).

Targeted lighting of objects and spaces in exterior environment is the main reserve of energy savings in towns and suburban areas: the light in proper amounts needed only in the 
"habitable" pedestrian and vehicle spaces (on road surfaces, the faces and bodies of the pedestrians) for functional purposes and certain amount is needed for aesthetic needs (on the facades of objects).

These requirements are partially reflected in existing regulations, partially known to science. They are executed by the right choice and setting of lighting devices with limited light distribution. Luminous balls and similar devices should be excluded from the range of products for outdoor lighting as they are both environmentally unfriendly and energy wasteful.

The most promising way to solve the energy efficiency problem is a complex design of lighting systems integrated in architectural forms and material objects of the urban environment that will make them the light-carrying objects and allows you to use also the "secondary", essentially free light, for example, light of windows and interiors, passing through light apertures, and light informational systems like media facades for lighting urban pedestrian spaces (Figure 5,6).

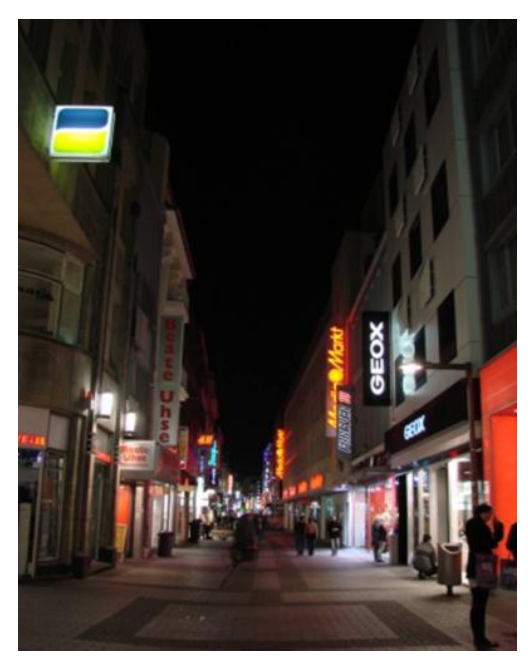

Fig. 5. Pedestrian street in Cologne, Germany, illuminated by the light of shop windows and lighting installations and advertising.

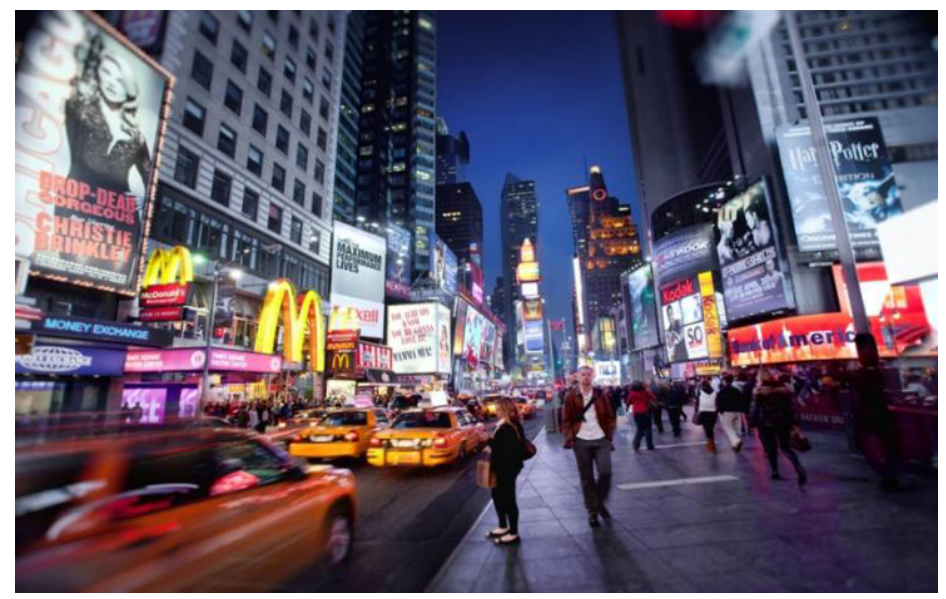

Fig. 6. Times Square in New York, where "free" static and dynamic light creates high lighting levels (up to 600 lux on the pedestrian's face). 


\section{Conclusion}

Address lighting is largely (but not entirely, because it is possible only at full refusal of artificial light, i.e. return to the Middle Ages and beyond) takes the edge off a rather speculative environmental problem of "light pollution of sky", at least during a snow-free period [7]. Energy-saving LED technologies which are increasingly used in various groups of fixed lighting installations, in the utilitarian street, facade and landscape, architectural and information and advertising lighting, not to mention the temporary (holidays, seasonal, fair, exhibition) lighting systems, also making an increasingly important contribution to solve this urgent problem.

Thus, energy efficiency in architecture is not limited only to energy-saving lighting systems, or even to electrical measures at all. The answer is presented in the table below: energy-efficient lighting design. Energy-efficient lighting design begins and develops in the architectural environment and is organically linked with both its dimensional and functional structure and its imaginative qualities, as well as with other activities, tools and technologies (Table 1).

Table 1. Energy efficient light design.

\begin{tabular}{|c|c|c|}
\hline \multicolumn{3}{|c|}{ ENERGY EFFICIENT LIGHT DESIGN } \\
\hline \multicolumn{3}{|l|}{$\nabla$} \\
\hline $\begin{array}{c}\text { INDOOR } \\
\text { (interior lightning) }\end{array}$ & \multirow[b]{2}{*}{4} & $\begin{array}{r}\text { OUTDOOR } \\
\text { (exterior lightning) }\end{array}$ \\
\hline $\begin{array}{l}\text { - Rational dimensional problem } \\
\text { solution } \\
\text { Maximum use (free access) of } \\
\text { daylight in rooms, also in conditions } \\
\text { of compact planning. } \\
\text {-Innovative technologies if natural } \\
\text { light } \\
\text { (hollow fiber, light wells, light- } \\
\text { refracting glasses, glasses regulated } \\
\text { by SZU, quality, high-quality mixed } \\
\text { lightening and etc). } \\
\text { - Improving standardization, methods } \\
\text { of calculation and design of natural } \\
\text { and artificial lighting } \\
\text { (scientific researches and } \\
\text { experimental designs) }\end{array}$ & & $\begin{array}{l}\text { - Integrated design of lighting systems } \\
\text { and elements of the urban environment } \\
\text { (general plan of the city illumination } \\
\text { and its fragments with the predicted } \\
\text { technical and economic parameters of } \\
\text { the lighting). } \\
\text { - Providing and considering complex } \\
\text { action of stationary lighting devices in } \\
\text { the urban space } \\
\text { (outdoor light }+ \text { architecture light + } \\
\text { highlighted information) } \\
\text { - Improving standardization, methods } \\
\text { of calculation and design of artificial } \\
\text { lighting } \\
\text { (scientific researches and experimental } \\
\text { designs) }\end{array}$ \\
\hline \multicolumn{3}{|c|}{$\begin{array}{l}\text { - Innovative tools and techniques of artificial lighting of spaces and objects (LEDs, etc.) } \\
\text { - Effective control system (multi-mode, programmable, interactive) } \\
\text { - High-quality operation of lighting installations (timely replacement of failed elements } \\
\text { of lighting installations, cleaning and adjustment of lighting equipment, compliance with } \\
\text { energy efficient lighting modes, etc.) }\end{array}$} \\
\hline
\end{tabular}

\section{References}

1. N. Zainordin, S. M. Abdullah, Z. A. Baharum, Procedia - Social and Behavioral Sciences, 36, 51-60 (2012) 
2. S. Paunović-Žarić, V. Radulović, E. Alihodžić-Jašarović, V. Murgul, Journal of Applied Engineering Science, 14(1), 140 - 147 (2016)

3. E. Kharkness, M. Mekhta, Regulirovanie solnechnoy radiatsii v zdaniyakh (Moscow, Stroyizdat. 1984)

4. N.V. Obolenskiy, Arkhitektura i solntse (Moscow, Stroyizdat. 1988)

5. V. Garcia Hansen, I. Edmonds, ISES Solar World Congress, 9, 14-19 (2003)

6. Yu. B. Ayzenberga, Spravochnaya kniga po svetotekhnike (Znak, Moscow, 2006)

7. N. I. Shchepetkov, Svetotekhnika, 5-6, 43-46 (1993)

8. Information on http://www.heliobus.com 